\title{
Lsr operon is associated with Al-2 transfer and pathogenicity in avian pathogenic Escherichia coli
}

\author{
Jiakun Zuo ${ }^{1,4}$, Huifang Yin ${ }^{2}$, Jiangang Hu ${ }^{1,3}$, Jinfeng Miao ${ }^{4}$, Zhaoguo Chen ${ }^{1}$, Kezong $\mathrm{Qi}^{3}$, Zhihao Wang ${ }^{1,3}$, \\ Jiansen Gong ${ }^{5}$, Vanhnaseng Phouthapane ${ }^{6}$, Wei Jiang ${ }^{1}$, Rongsheng $\mathrm{Mi}^{1}$, Yan huang ${ }^{1}$, Chen Wang ${ }^{7 *}$ \\ and Xiangan $\operatorname{Han}^{1 *}$
}

\begin{abstract}
The function of Autoinducer-2 (Al-2) which acts as the signal molecule of LuxS-mediated quorum sensing, is regulated through the Isr operon (which includes eight genes: IsrK, IsrR, IsrA, IsrC, IsrD, IsrB, IsrF, and IsrG). However, the functions of the Isr operon remain unclear in avian pathogenic Escherichia coli (APEC), which causes severe respiratory and systemic diseases in poultry. In this study, the presence of the Isr operon in 60 APEC clinical strains (serotypes O1, $\mathrm{O} 2$, and $\mathrm{O} 78$ ) was investigated and found to be correlated with serotype and has the highest detection rate in $\mathrm{O} 78$. The Al-2 binding capacity of recombinant protein LsrB of APEC (APEC-LsrB) was verified and was found to bind to $\mathrm{Al}-2$ in vitro. In addition, the Isr operon was mutated in an APEC strain (APEC94 $\triangle \mathrm{sr}(\mathrm{Cm})$ ) and the mutant was found to be defective in motility and Al-2 uptake. Furthermore, deletion of the Isr operon attenuated the virulence of APEC, with the LD 50 of APEC94 $\operatorname{Isr}(\mathrm{Cm})$ decreasing 294-fold compared with wild-type strain APEC94. The bacterial load in the blood, liver, spleen, and kidneys of ducks infected with APEC94 $\triangle \mathrm{Isr}(\mathrm{Cm})$ decreased significantly $(p<0.0001)$. The results of transcriptional analysis showed that 62 genes were up-regulated and 415 genes were down-regulated in APEC $94 \triangle \operatorname{ls}(\mathrm{Cm})$ compared with the wild-type strain and some of the down-regulated genes were associated with the virulence of APEC. In conclusion, our study suggests that Isr operon plays a role in the pathogenesis of APEC.
\end{abstract}

\section{Introduction}

Avian pathogenic Escherichia coli (APEC) infection causes severe respiratory and systemic diseases in poultry, resulting in serious losses to the poultry industry worldwide [1]. Elucidation of the underlying molecular mechanisms of APEC pathogenicity is crucial for controlling avian colibacillosis. The pathogenicity of APEC is determined by many factors, such as virulence factors, secretion systems, and quorum sensing [1-3]. The AI-2

\footnotetext{
*Correspondence: wangchen2001@126.com; hanxgan@163.com ${ }^{1}$ Shanghai Veterinary Research Institute, The Chinese Academy of Agricultural Sciences (CAAS), 518 Ziyue Road, Shanghai 200241, People's Republic of China

${ }^{7}$ College of Animal Science and Technology, Henan University of Science and Technology, No. 263 Kaiyuan Road, Luoyang 471023, People's Republic of China

Full list of author information is available at the end of the article
}

signal molecule of the LuxS/AI-2 quorum sensing system, which is derived from $S$-adenosylmethionine (SAM) by LuxS synthase, is widely distributed among bacteria. Currently, AI-2 is regarded as the most ubiquitous bacterial intercommunication signal and has been reported to play an important role in the regulation of many bacterial behaviors (including survival, biofilm formation, and virulence-related gene expression) [4] via AI-2 receptors.

There are two main types of AI-2 receptors, LuxP and LsrB receptors, which were initially characterized in Vibrio harveyi and Salmonella typhimurium, respectively. Although both LuxP and LsrB can bind to AI-2 in vitro, these two receptors have different structures [4].

In $S$. typhimurium, lsrB gene is located in $l s r$ operon, which was reported to function in importing AI-2 into the bacteria [5]. The $l s r$ operon consists of eight genes 
(lsrKRACDBFG) that encode an ATP binding cassette $(\mathrm{ABC})$ transporter. LsrK is a kinase that phosphorylates $\mathrm{AI}-2$ and is required for the regulation of AI-2 uptake [6]. LsrR is a repressor of the $l s r$ operon and during exponential growth, phosphor-AI-2 could inactivate LsrR and subsequently induce the transport of LsrACDBFG [7]. The $l s r A C D B$ genes encode the Lsr transport apparatus located in the cell membrane. The $l s r F$ gene encodes a coenzyme A-dependent thiolase that catalyzes the final step in the processing of the quorum sensing signal AI-2 [8]. LsrB is one of the substrate binding proteins of the $\mathrm{ABC}$ transport system that is responsible for the internalization of extracellular AI-2. Although orthologs of LsrB were found in S. typhimurium [9], E. coli [10], the plant symbiont Sinorhizobium meliloti [11], and the oral pathogen Aggregatibacter actinomycetemcomitans [12], in general, orthologs of the Lsr system are not broadly conserved in bacteria. Furthermore, although in E. coli, AI-2 is taken up intracellularly by the Lsr system, no typical LsrB-like receptor has been detected in APEC [4], and to date, there has been no report of the presence of a similar Lsr system in APEC strains.

Our previous study found that APEC strain DE17 (serotype O2) possessed the luxS gene (but lacked $l s r$ operon), and deletion of the $l u x S$ gene decreased APEC pathogenicity [2]. Interestingly, another APEC strain, APEC94 (serotype O78), was found to possess lsr-like operon in this study. These results revealed that $l s r$ operon had a different distribution rate in different serotypes APEC strains. Furthermore, $l s r$ operon is involved in transportation of AI-2, which may regulate some other physiological functions in bacteria. To date, the role of $l s r$ system in APEC strains remains unknown; however, we proposed that the Lsr system may be involved in regulating the virulence of APEC strains. Hence, in this study, we investigated: (1) the $l s r$ operon distribution among 60 APEC clinical strains of the three most common serotypes, (2) whether $l s r$ operon participates in AI-2 transportation, and (3) whether $l s r$ system is involved in regulating the virulence of APEC. Our findings provide a basis for further studies into the pathogenic mechanisms of APEC from a quorum sensing perspective.

\section{Materials and methods}

Bacterial strains, plasmids, and culture conditions

All of the strains and plasmids used in this study are listed in Table 1. The E. coli strains were grown in Lennox broth (LB, Oxoid, UK) or solid medium containing $1.5 \%$ agar at $37{ }^{\circ} \mathrm{C}$ overnight. $V$. harveyi strains were grown in marine broth (MB, Becton-Dickinson, Sparks, MD, USA) or solid medium containing 1.5\% agar at $28{ }^{\circ} \mathrm{C}$. Modified autoinducer bioassay (AB) medium was exclusively used for $V$. harveyi strain BB170 [13] for the detection of bioluminescence. The ingredients of $\mathrm{AB}$ were purchased from Amresco, USA. When needed, antibiotics (Sangon Biotech, Shanghai,

Table 1 Bacterial strains and plasmids used in this study

\begin{tabular}{|c|c|c|}
\hline Strains or plasmid & Relevant genotype and property & Source or references \\
\hline \multicolumn{3}{|l|}{ Escherichia coli strains } \\
\hline BL21 & DE3 & Invitrogen \\
\hline BL21 1 luxS & BL21 DE3/uxS deletion mutant strain & {$[23]$} \\
\hline MG1655 & & {$[16]$} \\
\hline DE17 & APEC serotype $\mathrm{O} 2$ & {$[2]$} \\
\hline DE17 $\triangle$ luxS $\triangle \mathrm{pfs}$ & DE17 luxS and pfs mutant strain & This study \\
\hline APEC94 & Wide type, isolated from sick chicken (serotype 078) & This study \\
\hline APEC94 $\triangle \operatorname{lsr}(C m)$ & Lacking of /sr operon & This study \\
\hline \multicolumn{3}{|l|}{ Salmonella strains } \\
\hline Salmonella typhimurium & $\mathrm{LT} 2$ & ATCC 14028 \\
\hline \multicolumn{3}{|l|}{ Vibrio harveyi strains } \\
\hline BB170 & BB120 luxN::Tn5 (sensor 1-, sensor 2+) & {$[13]$} \\
\hline BB152 & BB120 luxM::Tn5 (representing Al-2) & {$[21]$} \\
\hline \multicolumn{3}{|l|}{ Plasmids } \\
\hline pKD46 & The vector containing arabinose-inducible phage $\lambda$ Red recombinase $\left(A_{m p}\right)$ & {$[17]$} \\
\hline pACYC177-Isr & The Isr operon complement plasmid & This study \\
\hline pCold TF & Expression vector with $\mathrm{Amp}^{\mathrm{R}}$ & TaKaRa \\
\hline pKD3 & The plasmid contained chloramphenicol resistance $\left(\mathrm{Cm}^{\mathrm{R}}\right)$ & [17] \\
\hline pCold TF-IsrB & Recombinant plasmid contained /srB of APEC & This study \\
\hline
\end{tabular}


China) were added to the following final concentrations: $100 \mu \mathrm{g} / \mathrm{mL}$ ampicillin, $30 \mu \mathrm{g} / \mathrm{mL}$ chlorampheni$\mathrm{col}$, and $50 \mu \mathrm{g} / \mathrm{mL}$ kanamycin.

\section{Ethics statement}

According to the guidelines of the Institutional Animal Care and Use Committee (IACUS), one-day-old Cherry Valley ducklings purchased from Shanghai Zhuang Hang Duck Farm were cared for and maintained by the Shanghai Veterinary Research Institute of Chinese Academy of Agricultural Sciences (CAAS). All the animal experiments were approved by the Ethics Committee of CAAS (Permit No: CAAS-SHVRI-Po-2019-36).

\section{Isolates serotyping and sequencing and alignment of $I s r$ operon of APEC94}

Sixty clinical isolates of APEC (serotypes O1, O2, O78) were obtained from obviously diseased poultry in the provinces of Shanghai, Anhui, Jiangsu, Fujian, and Henan between 2007 and 2015. The DNA of the clinical isolates was extracted from overnight cultures using a boiling procedure according to a previously reported protocol [14]. The serotypes of APEC strains were determined using a multiplex PCR method as described previously [15]. To investigate the distribution of the $l s r$ operon among APEC strains, primers $(l s r K-\mathrm{F} / \mathrm{R}$, $l s r R-\mathrm{F} / \mathrm{R}, l s r A-\mathrm{F} / \mathrm{R}, l s r C-\mathrm{F} / \mathrm{R}, l s r D-\mathrm{F} / \mathrm{R}, l s r B-\mathrm{F} / \mathrm{R}, l s r F-$ $\mathrm{F} / \mathrm{R}, l s r G-\mathrm{F} / \mathrm{R}$, Table 2) were designed for the 8 genes from the $l s r$ operon according to the corresponding sequences from strain MG1655 [16]. In addition, the PCR products of APEC94 were sequenced (by Invitrogen) and aligned with the corresponding sequences from strain MG1655 and Salmonella strain LT2.

\section{Construction and identification of Isr mutant strain and its complementation of APEC94}

The mutant strain APEC94 $\Delta \mathrm{lsr}(\mathrm{Cm})$ was generated using the lambda Red recombinase method [17]. Briefly, the upstream and downstream fragments of the $l s r$ operon were amplified from the APEC 94 genome by PCR using the primers $l s r-U F / l s r-U R$ and $l s r-D F / l s r-$ $D R$. The chloramphenicol resistance cassette $(\mathrm{Cm})$ was amplified from plasmid pKD3 with primers $l s r-C F / l s r-$ $C R$. All of these PCR products (including the upstream and downstream fragments and the $\mathrm{Cm}$ cassette) were then used as templates for amplifying the recombinant fragment with primers $l s r-U F / l s r-D R$ by overlap PCR. One microgram of the recombinant PCR product was then added to $100 \mu \mathrm{L}$ of APEC94 competent cells containing the lambda Red recombinase expression plasmid pKD46. Electroporation was performed as described previously. Positive clones were selected on
LB plates containing $10 \mu \mathrm{g} / \mathrm{mL}$ chloramphenicol and were verified by PCR using primer pairs $l s r-U F / l s r-D R$ and $l s r B-F / l s r B-R$.

For functional complementation, lsr operon sequence (containing $9440 \mathrm{bp}$ ) was amplified from the chromosomal DNA of APEC94 with the primers PstI-lsr-CF/ PstI- $l s r-C R$ and cloned into pACYC177 to yield the plasmid pACYC177-lsr.

The mutant strain APEC $94 \Delta \mathrm{lsr}(\mathrm{Cm})$ was transformed with pACYC177-lsr. The complementation strain was named $l s r$-APEC $94 \Delta \mathrm{lsr}$. The primer sequences used are listed in Table 2.

\section{The effect of Isr operon on growth, biofilm formation and motility of APEC94}

Growth curves were determined as described previously [18]. Briefly, equal volume $(1 \mathrm{~mL})$ of APEC94, APEC $94 \Delta \operatorname{ls}(\mathrm{Cm})$ and lsr-APEC94 $\Delta \mathrm{lsr}$ culture $\left(\mathrm{OD}_{600}=1.0\right)$ were inoculated into $100 \mathrm{~mL}$ of $\mathrm{LB}$ culture media and incubated at $37{ }^{\circ} \mathrm{C}$ with shaking, respectively. The $\mathrm{OD}_{600}$ value of each sample was then examined at $1 \mathrm{~h}$ intervals. The ability of biofilm formation was assessed by crystal violet staining method. The bacteria were cultured to a logarithmic phase and centrifuged at $4{ }^{\circ} \mathrm{C}, 6000 \mathrm{rpm}$. Then the cells were resuspended with the M9 medium (containing $0.2 \%$ fructose) after washing twice with PBS and adjusted to $\mathrm{OD}_{600}=0.1$. The bacteria were at incubated at $25{ }^{\circ} \mathrm{C}$ for $18 \mathrm{~h}$ in a sterile $96-$ well plate $(200 \mu \mathrm{L}$ per well and each group for 5 repeats), then washed with PBS (200 $\mu \mathrm{L}$ per well), and stained with $0.1 \%$ crystal violet at $37^{\circ} \mathrm{C}$ for $15 \mathrm{~min}$. The plates were washed with PBS for three times and dried. Finally, 95\% ethanol was added into the wells and the $\mathrm{OD}_{595}$ was measured using microplate reader to analyze the biofilm formation of APEC94, APEC $94 \Delta \mathrm{lsr}(\mathrm{Cm})$ and lsr-APEC94 $\triangle \mathrm{lsr}$, respectively.

The swimming motility of APEC94, APEC $94 \Delta \mathrm{lsr}(\mathrm{Cm})$ and $l s r$-APEC $94 \Delta \mathrm{lsr}$ bacterial cells was assessed on soft agar plates ( $1 \%$ tryptone, $0.8 \%$ glucose, $0.5 \% \mathrm{NaCl}, 0.3 \%$ agar) as described previously with some modifications [19]. Briefly, the bacteria were cultured to logarithmic phase and pelleted by centrifugation. The resulting pellet was washed and suspended in phosphate-buffered saline (PBS) and the final $\mathrm{OD}_{600}$ was adjusted to 1.0. A total of $6 \mu \mathrm{L}$ of bacterial suspension was loaded onto the soft agar plate and incubated for $24 \mathrm{~h}$. The swimming motility was assessed by measuring the migration diameter of bacteria from the center toward the periphery on the agar plate.

\section{Al-2 bioassay}

The detection of AI-2 activity was performed according to a previously described method [3,20]. Briefly, cell-free culture fluid (CF) of APEC strains and mutants was prepared as follows. Bacteria were cultured in LB 
Table 2 Primers used in this study

\begin{tabular}{|c|c|c|c|}
\hline Primers & Oligonucleotide sequence $\left(5^{\prime}\right.$ to $\left.3^{\prime}\right)$ & Description & $\begin{array}{l}\text { Product } \\
\text { size (bp) }\end{array}$ \\
\hline Isrk-F & CTATAACCCAGGCGCTTTCCATA & Partial sequence of /srk & 1593 \\
\hline IsrK-R & ATGGCTCGACTCTTTACCCTTTC & & \\
\hline IsrR-F & TTAACTACGTAAAATCGCCGCTG & Partial sequence of $/ s r R$ & 954 \\
\hline IsrR-R & ATGACAATCAACGATTCGGCAAT & & \\
\hline LsrA-F & ATGCAAACGAGTGATACCCGCGC & Partial sequence of IsrA & 1539 \\
\hline Isra-R & ACTTCAGCATGACGCCTCCTGAC & & \\
\hline IsrC-F & CTGAAGTTTATTCAGAACAACCGTG & Partial sequence of $/ s r C$ & 826 \\
\hline IsrC-R & TATCGATCTGCGTCAGGAACCAT & & \\
\hline IsrD-F & GCCGCATAATGCGTATTCGCTAC & Partial sequence of IsrD & 1003 \\
\hline IsrD-R & CTTTATGGCAATGGGTTATTGGC & & \\
\hline $\mid s r B-F$ & ATGACACTTCATCGCTTTAAGA ${ }^{a}$ & Partial sequence of $/ s r B$ & 826 \\
\hline$I s r B-R$ & CTGAAATTTTGCCTTGCTGAAC ${ }^{a}$ & & \\
\hline IsrF-F & GTAAAGATTTTCGTACCGATCAAC & Partial sequence of IsrF & 657 \\
\hline IsrF-R & TTTTACCGCCAGCAATAACAATG & & \\
\hline IsrG-F & ATGCACGTCACACTGGTTGAAAT & Partial sequence of $/ s r G$ & 291 \\
\hline IsrG-R & TCACGGCATCAAACCATTGAACA & & \\
\hline APEC94|sr-F & TCCCTTGAATATCGTACTGG & Using for DNA sequencing of Isr operon & \\
\hline APEC94|sr-R & TGCGCTTCGATGTCTTAC & & \\
\hline pCold-F1 & CCCAAGCTTGAAATCGTATTTGCCGAT & Using for identification of IsrB-APEC recombinant plasmid & 1150 \\
\hline pCold-R & GGCAGGGATCTTAGATTCTG & & \\
\hline Isr-UF & TCTAAAAGAAGGGAAATAAG ${ }^{\mathrm{b}}$ & The upstream sequence of Isr operon & 763 \\
\hline Isr-UR & CCAGCCTACA GCATGGTACAAGCTGAATC & & \\
\hline Isr-CF & TGTACCATGCTGTAGGCTGGAGCTGCTT & Chloramphenicol resistance cassette (cat) & 1013 \\
\hline IST-CR & CATTGAACAGCATATGAATATCCTCCTTAGTTC & & \\
\hline Isr-DF & TATTCATATGCTGTTCAATGGGTTGATGC & The downstream sequence of Isr operon & 638 \\
\hline Isr-DR & TGGTGATAGTAGGTGGTTCGb & & \\
\hline Pstl-Isr-CF & $\begin{array}{l}\text { AAAACTGCAGGGTCTGTATTGAGTGTTAGTT } \\
\text { GGAGGTGGGC }\end{array}$ & The Isr operon complement sequence & 9440 \\
\hline Pstl-Isr-CR & AAAACTGCAGCAGTTGCGGATGTCTGCTT' & & \\
\hline LsrB-BamHI-F & CGCGGATCCATGACACTTCATCGCTTTA ${ }^{d}$ & The ORF sequence of $/ s r B$ & 1023 \\
\hline LsrB-HindIII-R & CCACTTTCAACGAGCTGATG ${ }^{\mathrm{e}}$ & & \\
\hline fimH-RTF & GTGCCAATTCCTCTTACCGTT & Partial DNA sequence of fimbrial protein FimH & 165 \\
\hline fimH-RTR & TGGAATAATCGTACCGTTGCG & & \\
\hline fliD-RTF & TTCAGACGCAGTTGAAATCG & Partial DNA sequence of flagellar filament capping protein FliD & 184 \\
\hline fliD-RTR & TTACCATCGCCAACAATCAA & & \\
\hline fhA-RTF & CGGCATCGTACTCTGGAACT & Partial DNA sequence of flagellar biosynthesis gene flhA & 172 \\
\hline flhA-RTR & CATTACCCATCCGTTCGTTC & & \\
\hline dosP-RTF & ATAAACCCACGCCCATATCA & Partial DNA sequence of oxygen-sensing cyclic-di-GMP phosphodiesterase DosP & 194 \\
\hline dosP-RTR & GGCGTTATCCGTGAACTTGT & & \\
\hline pgaA-RTF & GGCAATGGTCTCCTTGTGAT & Partial DNA sequence of poly-beta-1,6 N-acetyl-D-glucosamine export porin PgaA & 195 \\
\hline pgaA-RTR & GATCATCTTGGCGCGTTATT & & \\
\hline fhuD-RTF & AACTATCGCCTGTGGGTCAG & Partial DNA sequence of iron-hydroxamate transporter substrate-binding subunit & 153 \\
\hline fhuD-RTR & TGCCAGCATTTCTGATGAAG & & \\
\hline dnaE-RTF & GATTGAGCGTTATGTCGGAGGC & Partial DNA sequence of the internal control dnaE & 80 \\
\hline dnaE-RTR & GCCCCGCAGCCGTGAT & & \\
\hline
\end{tabular}


at $37{ }^{\circ} \mathrm{C}$ and pelleted by centrifugation at $12000 \mathrm{~g}$ at $4{ }^{\circ} \mathrm{C}$ for $10 \mathrm{~min}$. Then, CF samples were obtained by filtering the resulting supernatants via a $0.22-\mu \mathrm{m}$ filter (EMD Millipore, Bedford, MA, USA). The reporter strain $V$. harveyi BB170 was diluted to 1:5000 in fresh $\mathrm{AB}$ medium. Then, $20 \mu \mathrm{L}$ of the bacterial CF sample to be tested was added to $180 \mu \mathrm{L}$ of bacterial culture and incubated at $30^{\circ} \mathrm{C}$ for $4 \mathrm{~h}$. After incubation, $200-\mu \mathrm{L}$ aliquots were added to white, flat-bottomed, 96-well plates (Thermo Labsystems, Franklin, MA, USA) for the detection of AI-2 activity. A positive control was obtained from overnight cultures of BB152 [21], while the CF from DE17 $\Delta$ luxS $\Delta$ pfs strain (constructed in our laboratory) was used as a negative control. Luminescence was measured with a microplate reader in luminescence mode (Synergy2, BioTek, USA). The AI-2 activity of $V$. harveyi $\mathrm{BB} 170$ is expressed in relative light units (RLU). All samples were assayed in triplicate.

\section{Determination of the Al-2 internalization curve}

AI-2 internalization curves of APEC94 and APEC $94 \Delta \mathrm{lsr}(\mathrm{Cm})$ were determined as described previously [22]. Briefly, APEC94 and APEC94 $\Delta \mathrm{lsr}(\mathrm{Cm})$ were cultured to logarithmic phase and the bacteria were harvested via centrifugation. Bacteria were resuspended in PBS, washed twice, and then the $\mathrm{OD}_{600}$ was adjusted to 1.0. The CF samples were obtained by filtration of the resulting supernatant through a $0.22-\mu \mathrm{m}$ filter to assess the endogenous AI-2 levels of APEC94 and the mutant strain.

To generate AI-2 internalization curves for strains APEC94 and APEC $94 \Delta \mathrm{lsr}(\mathrm{Cm}), 10 \mathrm{~mL}$ of bacterial culture with a final concentration of $36 \mu \mathrm{M}$ commercial AI-2 was incubated at $37{ }^{\circ} \mathrm{C}$ with shaking. The $\mathrm{CF}$ samples of each strain were obtained as described previously every $2 \mathrm{~h}$. The CF from BB152 was used as the positive control and the CF from the DE17 luxS and pfs double mutant strain was used as the negative control (Table 1).

The detection of AI-2 activity was performed as described previously. The AI-2 activity of $V$. harveyi BB170 is expressed in RLU. All samples were assayed in triplicate.

\section{Expression of $\mathrm{LsrB}$ and $\mathrm{Al}-2$ binding assays}

To determine whether the LsrB of APEC94 can bind to AI-2, the $l s r B$ gene was expressed in E. coli strains BL21 and BL21 $\Delta$ luxS [23]. Recombinant LsrB fusion proteins were purified by Ni-chelating affinity chromatography after ultrasonic decomposition and eluted using a solution containing $50 \mathrm{mM}$ imidazole. The LsrB fusion proteins were investigated by SDS-PAGE gel scan analysis.

An AI-2 release assay was performed according to a previously described method with some modifications
[23]. The purified LsrB fusions ( $3 \mathrm{mg} / \mathrm{mL}$ ) isolated from BL21 or BL21 1 luxS strains were incubated for $10 \mathrm{~min}$ at $55{ }^{\circ} \mathrm{C}$ to release endogenous $\mathrm{AI}-2$. After incubation, the LsrB proteins were removed by ultrafiltration (10 000Da cut-off; EMD Millipore), and the filtered reaction products were tested for AI-2 activity using a $V$. harveyi BB170 bioassay, performed as described above. Sterile PBS with commercial AI-2 was used as a positive control.

An assay of the binding of recombinant LsrB to exogenous AI-2 was performed according to a previously described method with some modifications [23]. Purified LsrB fusions $(3 \mathrm{mg} / \mathrm{mL})$ isolated from strains BL21 or BL21 $\Delta$ luxS were incubated with exogenous AI-2 $(40 \mu \mathrm{M})$ for $1 \mathrm{~h}$ at $37^{\circ} \mathrm{C}$. After incubation, the LsrB fusion proteins were removed by ultrafiltration (10 000-Da cut-off; EMD Millipore), and the filtered reaction products were tested for AI-2 activity using a V. harveyi BB170 bioassay as detailed above. Sterile PBS with commercial AI-2 was used as a positive control.

\section{Determination of the lethal dose of APEC94 and APEC94 $\triangle \mathrm{lsr}(\mathrm{Cm})$}

To verify whether deletion of the $l s r$ operon would influence the virulence of APEC strains, 9-day-old Cherry Valley ducklings were used to determine the $\mathrm{LD}_{50}$ of the bacteria as described previously [24]. Briefly, for APEC94 and APEC $94 \Delta \mathrm{lsr}(\mathrm{Cm}), 40$ ducklings of each group were divided evenly into five groups and injected intramuscularly into legs with $10^{9}, 10^{8}, 10^{7}, 10^{6}$, or $10^{5} \mathrm{CFU}$ of bacteria, respectively. Mortality was monitored until 7 days post-infection and the $\mathrm{LD}_{50}$ was calculated according to the Reed-Muench formula [25].

\section{The bacterial loads of APEC94 and APEC94AIsr $(\mathrm{Cm})$ in vivo}

The bacteria strains were grown to an $\mathrm{OD}_{600}$ value of 1.0, washed three times using sterile PBS, and subsequently suspended in PBS. For each group, eight 9-day-old Cherry Valley ducklings were injected with $10^{9} \mathrm{CFU}$ of bacteria. Ducklings were euthanized and dissected $24 \mathrm{~h}$ post-infection. The bacterial loads of each sample in the blood, liver, spleen, and kidney of the infected ducklings were counted by the plate dilution method as described previously [1].

\section{Collection of bacterial samples for transcriptional analysis}

The transcriptional levels of APEC, APEC94 and APEC $94 \Delta \operatorname{lsr}(\mathrm{Cm})$ cells were determined as described with some modification [26]. To evaluate the effects of the $l s r$ operon on the transcriptional levels of APEC, APEC94 and APEC $94 \Delta \operatorname{sr}(\mathrm{Cm})$ cells were collected from culture in $\mathrm{LB}$ medium when the $\mathrm{OD}_{600}$ was 1.0 by centrifugation at $12000 \mathrm{rpm}$ for $5 \mathrm{~min}$. The collected cells were washed with PBS $(\mathrm{pH}=7.4)$ and centrifuged. Total RNA 
was extracted from the bacterial cell pellet using Trizol RNA Isolation Reagent (Invitrogen, Carlsbad, CA, USA) according to the manufacturer's protocol. RNA quantity and quality were evaluated by the $\mathrm{OD}_{260} / \mathrm{OD}_{280}$ ratio using a Nanodrop spectrophotometer. RNA integrity was assessed by standard denaturing agarose gel electrophoresis [26]. mRNA was enriched by removing rRNA from the total RNA samples using the Ribo-zero kit. Then, the transcriptome libraries of APEC94 and APEC $94 \Delta \operatorname{lsr}(\mathrm{Cm})$ were constructed and sequenced using the Illumina HiSeqTM2500/MiseqTM sequencing technique. The main differentially expressed genes were analyzed by gene ontology (GO). Pathway analysis for differentially expressed genes was performed according to the latest Kyoto Encyclopedia of Genes and Genomes (KEGG) database. The readcount obtained was firstly normalized according to the method of TMM (Trimmed mean of M-values) and the $p$ value was calculated abided by the Poisson distribution. Differentially expressed genes were defined by a fold change in expression of $>2$ and q value $<0.005$. Volcano Plot filtering was performed to identify the statistically significant differentially expressed genes between APEC94 and APEC94 $\Delta \mathrm{lsr}(\mathrm{Cm})$.

\section{The effect of Isr operon on transcriptional levels of virulence-related genes}

To analyze the effect of $l s r$ operon on the expression of the genes involved in virulence of APEC fim $H$, fliD, flhA, dosP, $p g a A$ and $f h u D$ [27-32], their expression was evaluated by quantitative real time-PCR (Table 2).

Briefly, bacteria were grown to the logarithmic phase $\left(\mathrm{OD}_{600}=1.0\right)$ in LB broth and total RNA was extracted from these bacteria using TRIzol reagent (Invitrogen Corporation, USA) according to the manufacturer's protocol. The RNA was treated with PrimeScript ${ }^{\mathrm{TM}} \mathrm{RT}$ reagent Kit with gDNA Eraser (TAKARA Corporation, Japan) in order to remove genomic DNA, and then reverse transcribed into cDNA (complementary DNA). The SYBR Green based two-step qRT-PCR (TB Green ${ }^{\circledR}$ Premix Ex Taq ${ }^{\mathrm{TM}}$ II, TAKARA Corporation, Japan) amplification was performed as described previously with some modification. Relative changes in gene expression level were assessed using the $2^{-\Delta \Delta C t}$ method [2]. The $d n a E$ gene was used as an internal control. The final qRT-PCR data were presented as the means of three separate experiments.

\section{Results}

\section{Distribution of the Isr operon between different serotype} strains

The PCR assay results confirmed that 41 of the 60 APEC isolates (68.3\%) possessed lsr operon. Interestingly, among these 41 isolates, five possessed an incomplete $l s r$ operon.
The distribution of lsr operon was found to be different for different serotypes with positive detection rates in serotypes O1, O2, and O78 of $68.8 \%$ (11/16), 40.9\% $(9 / 22)$, and $95.5 \%(21 / 22)$, respectively. There was one isolate with an incomplete $l s r$ operon in serotype O1, two isolates in serotype $\mathrm{O} 2$, and two isolates in serotype O78, respectively (Additional file 1).

\section{Analysis of the Isr operon in APEC94}

According to nucleotide sequence alignments, the eight genes in the $l s r$ operon of APEC94 shared high homology to MG1655 (>98\%), and 66-79\% homology to Salmonella strain LT2 (Additional file 2).

According to amino acid sequence alignments, the proteins encoded by the eight genes in the lsr operon of APEC94 shared high homology to MG1655 (> 99\%), and 71-89\% homology to Salmonella strain LT2 (Additional file 3$)$.

\section{Identification of Isr operon mutant and complementary strains of APEC94, analysis of the effect of Isr operon on the characteristics of APEC94}

The deletion of the $l s r$ operon in mutant strain APEC $94 \Delta \operatorname{lsr}(\mathrm{Cm})$ was confirmed by PCR (Figure 1A). A 2414-bp PCR product was amplified from the mutant strain APEC94 $\Delta \mathrm{lsr}(\mathrm{Cm})$ with primers $l s r$-UF/lsr-DR (Figure 1B, lane 2), whereas no product was obtained from the wild-type strain APEC94 within a limited amplification time (Figure 1B, lane 1). When primers $l s r B-\mathrm{F} / l s r B-\mathrm{R}$ were used, an 826 -bp PCR product was amplified from the wild-type strain APEC94 (Figure 1B, lane 4$)$ and $l s r$ complementary strain $l s r$-APEC $94 \Delta l s r$ (Figure 1B, lane 6), whereas no PCR product was amplified from APEC94 $\triangle \mathrm{lsr}(\mathrm{Cm})$ (Figure 1B, lane 5). Growth curves of APEC94, lsr mutant strain APEC94 $\Delta \mathrm{lsr}(\mathrm{Cm})$ and $l s r$ complementary strain $l s r$-APEC94 $\Delta$ lsr (Figure $2 \mathrm{~A}$ ) showed that there was no significant difference in growth during culture in LB $(p>0.05)$. The crystal violet staining results (Figure $2 \mathrm{~B}$ ) showed that $l s r$ operon did not affect biofilm formation of APEC94, APEC $94 \Delta \mathrm{lsr}(\mathrm{Cm})$ and $l s r$-APEC $94 \Delta \mathrm{lsr}(p>0.05)$. As shown in Figure $2 \mathrm{C}$, compared with the wild-type strain, the motility of APEC $94 \Delta \operatorname{lsr}(\mathrm{Cm})$ was significantly decreased $(p<0.01)$ while the motility of complementary strain $l s r$-APEC $94 \Delta$ lsr was restored $(p>0.05)$.

\section{The Isr operon influenced the uptake of AI-2 in APEC94}

The CF from APEC94 and APEC $94 \triangle \mathrm{lsr}(\mathrm{Cm})$ at logarithmic phase tested positive in a bioluminescence detection assay. However, the RLU value of APEC94 $\Delta \mathrm{lsr}(\mathrm{Cm})$ 


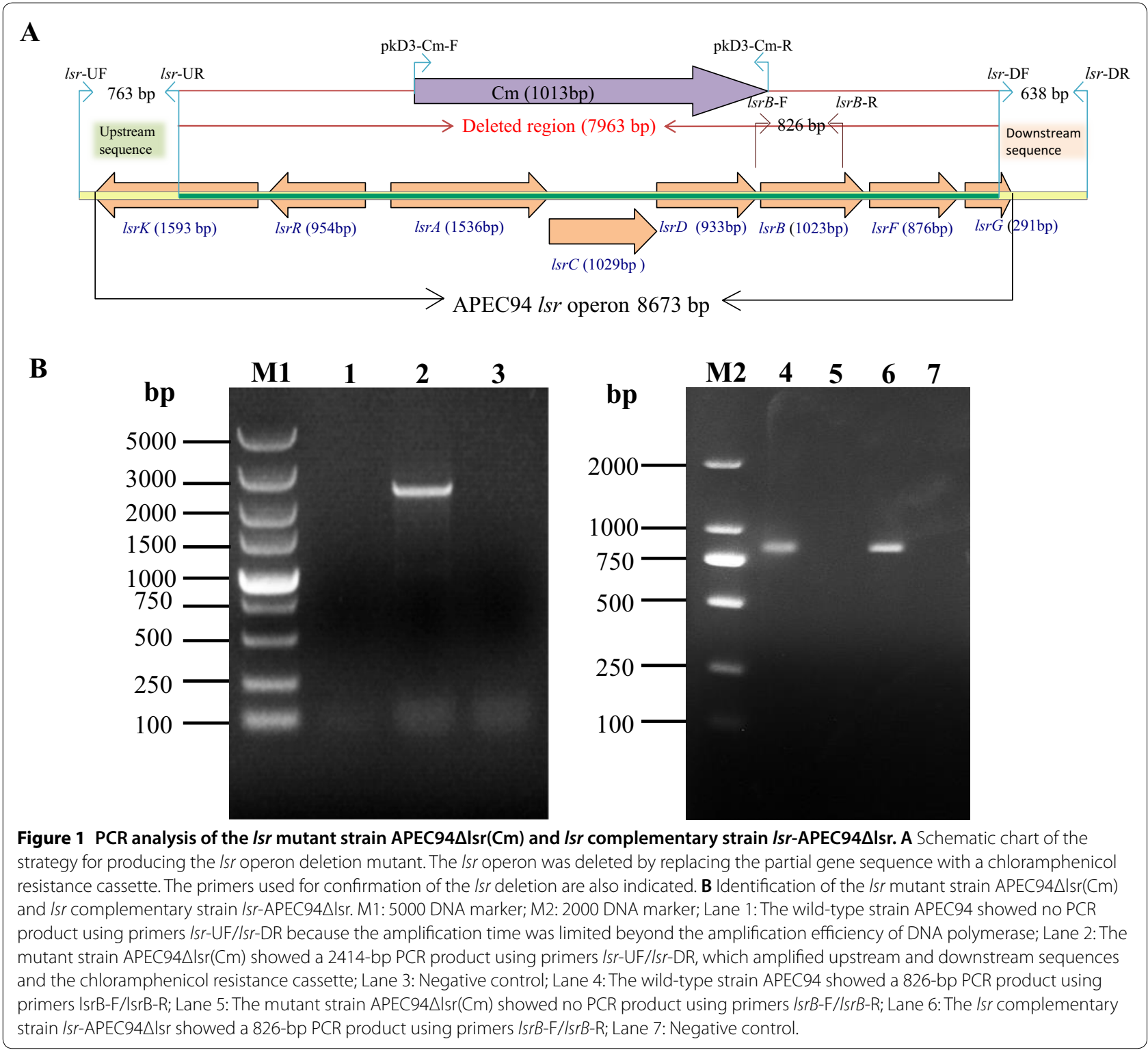

was 2.26-fold higher than that of the wild-type strain (Figure 3A).

When 37.0 $\mu \mathrm{M}$ AI-2 was added to the APEC94 cell suspensions, AI-2 activity was rapidly reduced after $4 \mathrm{~h}$, reaching almost negative control levels by $8 \mathrm{~h}$. By contrast, when $37.0 \mu \mathrm{M}$ AI-2 was added to the APEC $94 \Delta \operatorname{lsr}(\mathrm{Cm})$ cell suspensions, AI-2 activity was maintained at a high level throughout the $8 \mathrm{~h}$ (Figure 3B). The results indicated that APEC94 could generate an AI2-like molecule, the $l s r$ operon could influence the uptake of AI-2 in APEC94, and deletion of the lsr operon could impede AI-2 internalization.
LsrB could bind to both endogenous and exogenous Al-2

The recombinant fusion protein APEC-LsrB was successfully expressed in soluble form in both E. coli BL21 and BL21 $\Delta$ luxS strains. The fusion proteins were purified and the concentrations in strain BL21(DE3) and BL21 $\Delta$ luxS (DE3) were $0.52 \mathrm{mg} / \mathrm{mL}$ and $1.18 \mathrm{mg} / \mathrm{mL}$, respectively.

The results of the AI-2 release assay showed that recombinant APEC-LsrB (BL21) bound to endogenous AI-2 (produced by the wild-type $E$. coli strain BL21) and released AI-2 after protein denaturation at $55{ }^{\circ} \mathrm{C}$ (Figure $4 \mathrm{~A}$ ). However, recombinant APECLsrB (BL21 1 luxS) could not release endogenous AI-2 affecting the AI-2 synthesis pathway. 


\section{A}



B
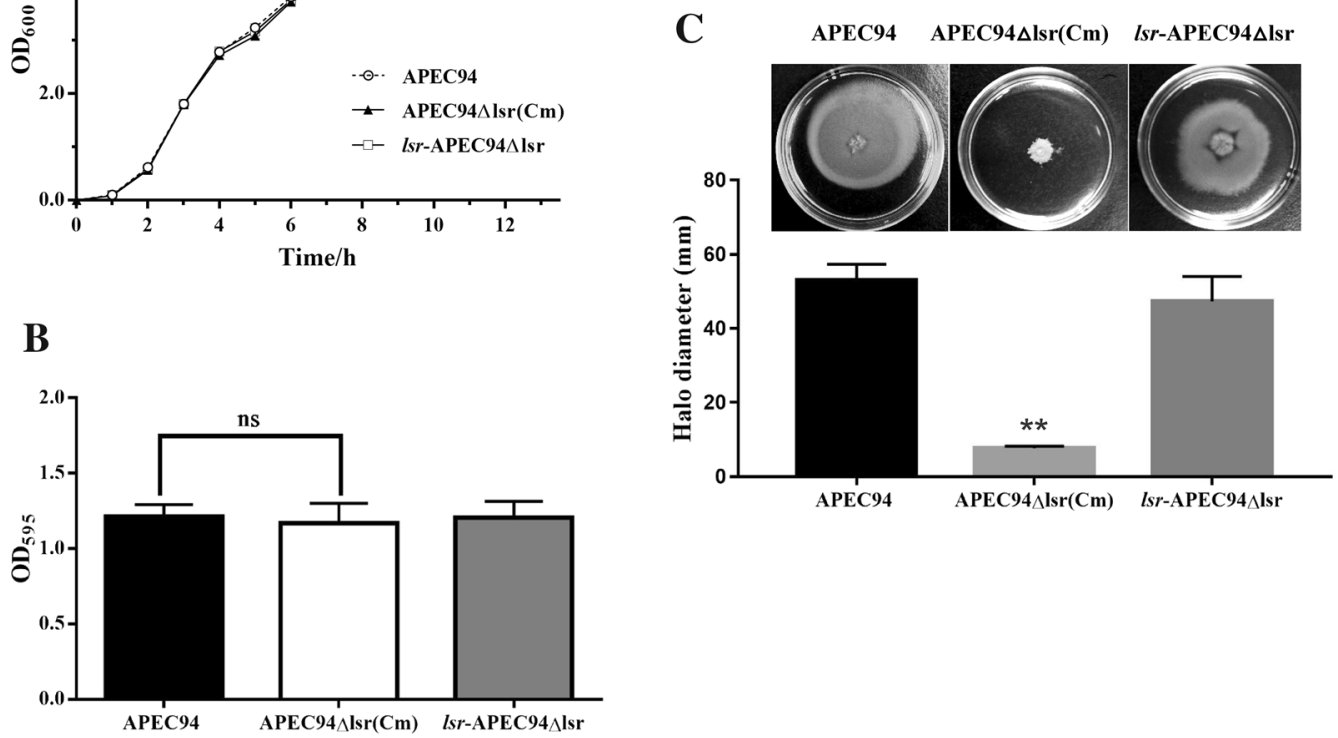



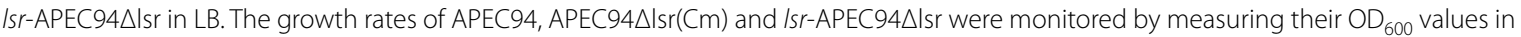
LB medium at 1-h intervals for $12 \mathrm{~h}$, respectively. After $12 \mathrm{~h}$ of culturing, there was no significant difference in the growth rate of APEC94, APEC $94 \Delta \mathrm{Isr}(\mathrm{Cm})$ and Isr-APEC94 $\triangle \mathrm{lsr}$ grown in LB broth $(p>0.05)$. Each value represents the average of three independent experiments. Significant differences were detected using the Student's $t$ test with SPSS v19.0 software. B Biofilm formation. There was no significant difference in biofilm

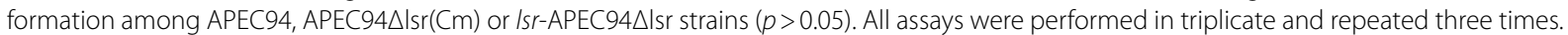

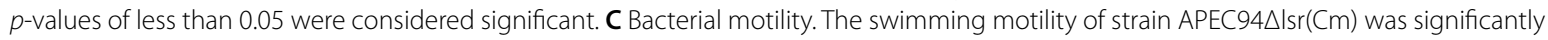
lower than that of the wild-type APEC94 strain $(p<0.01)$ while the swimming motility of complementary strain Isr-APEC94 $\triangle$ Isr was restored. The experiment was repeated three times and all samples were measured in triplicate. $p$ values less than 0.05 were considered significant.

\section{A}

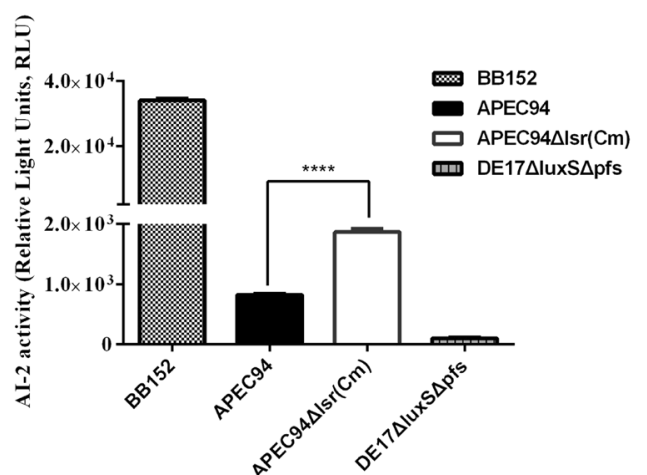

B

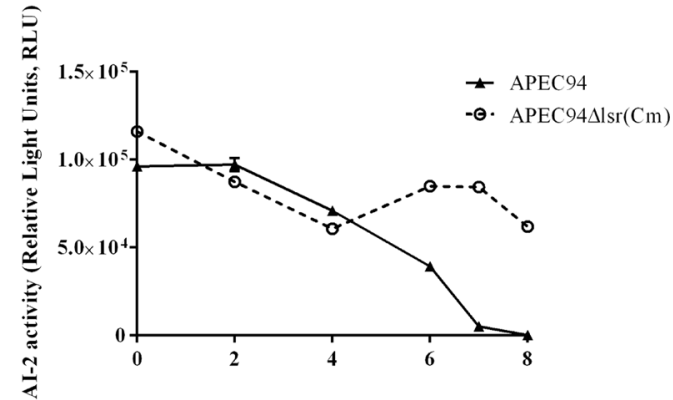

Figure 3 Influence of the Isr operon on the bacterial AI-2 internalization curve. A The Al-2 activity of bacterial cell-free culture fluids was


RLUs) was 2.26-fold higher than the value of APEC94 (823 RLUs) ( $p<0.05)$. B In the Al-2 internalization curve of APEC94, the activity of Al-2 began to decrease rapidly at $4 \mathrm{~h}$ and at $8 \mathrm{~h}$ the Al-2 activity was nearly negative, while the activity of Al-2 in APEC $94 \Delta \mathrm{Is}(\mathrm{Cm})$ cell suspensions remained high during the $8 \mathrm{~h}(p<0.001)$. All samples were measured in triplicate. $p$ values less than 0.05 were considered significant. 
A

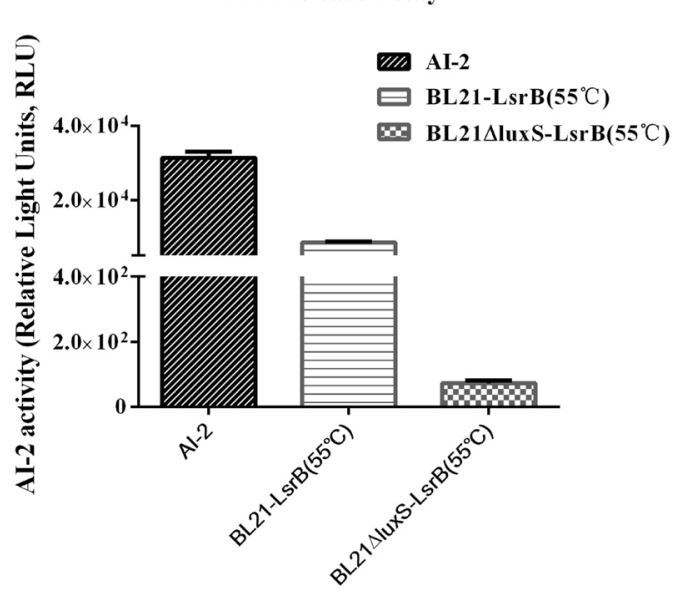

B

AI-2 Binding Assay

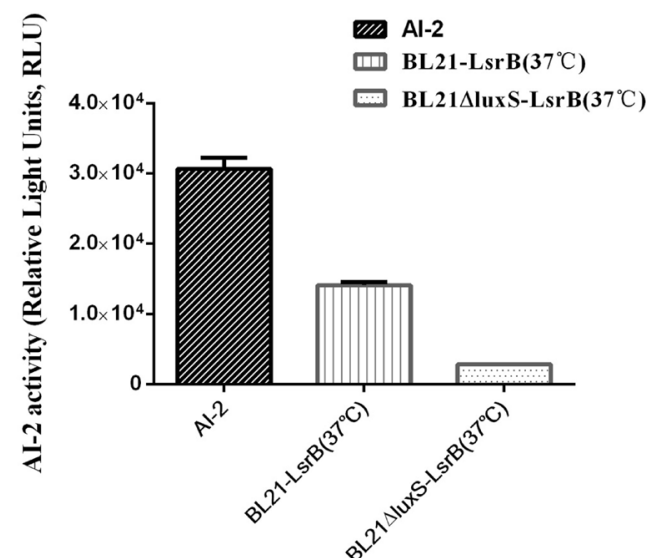

Figure 4 Binding of APEC-LsrB to Al-2 using an Al-2 assay. A The activity of APEC-LsrB binding to endogenous Al-2 was evaluated by an Al-2 assay, which showed that the recombinant APEC-LsrB (BL21) bound to endogenous Al-2 produced by wild-type BL21 and released Al-2 at $55^{\circ} \mathrm{C}$. However, the luxS mutant BL21 $\triangle$ luxS did not produce Al-2 so that no Al-2 could be released from APEC-LsrB (BL21 $\triangle$ luxS). B The activity of APEC-LsrB binding to exogenous Al-2 was evaluated by an Al-2 assay, which showed that APEC-LsrB (BL21 $\Delta$ luxS) could bind to exogenous Al-2, resulting in low Al-2 activity in cell-free culture fluid (CF). However, APEC-LsrB (BL21) could not bind to exogenous Al-2 as it was hindered by endogenous Al-2 (produced by wild-type BL21), which resulted in high Al-2 activity in CF.

An AI-2 binding assay revealed that $3 \mathrm{mg} / \mathrm{mL}$ of recombinant APEC-LsrB (BL21 luxS) could bind to exogenous AI-2 $(40 \mu \mathrm{M})$, whereas recombinant APEC-LsrB (BL21) could not bind to exogenous AI-2 $(40 \mu \mathrm{M})$ since it had already bound to endogenous AI-2 (Figure 4B).

\section{Deletion of the Isr operon reduced bacterial virulence}

As shown in Table 3, the $\mathrm{LD}_{50}$ values of the wild-type and mutant strains were determined to be $8.66 \times 10^{5} \mathrm{CFU}$ and $2.55 \times 10^{8} \mathrm{CFU}$, respectively, representing a 294-fold decrease in virulence for the mutant strain APEC $94 \Delta \mathrm{lsr}(\mathrm{Cm})$ compared with the wild-type strain.

The bacterial loads of APEC $94 \Delta \mathrm{lsr}(\mathrm{Cm})$ in infected blood, liver, spleen, and kidney were significantly lower than those infected with the wild-type strain APEC94, being decreased by 38.5-, 1639-, 316 667-, and 753-fold, respectively (Figure 5 and Table 4). Statistical analysis of the results using the SPSS analysis software showed that the bacterial loads of APEC $94 \Delta \mathrm{lsr}(\mathrm{Cm})$ in all samples were significantly decreased as a result of deletion of the $l s r$ operon compared with the wild-type strain APEC94 $(p<0.0001)$.

\section{Determination of differentially expressed genes and pathway analysis}

The results of transcriptional analysis showed that 62 genes were up-regulated and 415 genes were down-regulated in APEC $\triangle \mathrm{lsr}(\mathrm{Cm})$ compared with wild-type strain APEC94 (Figure 6A). The up- and down-regulated genes

Table 3 The LD $_{50}$ of strains APEC94 and APEC94DIsr(Cm)

\begin{tabular}{|c|c|c|c|c|c|c|}
\hline APEC strains & Challenge dosage & No. of ducks & Mortality & Living No. & Mortality rate (\%) & $\mathrm{LD}_{50}(\mathrm{CFU})$ \\
\hline \multirow[t]{5}{*}{ APEC94 } & $10^{9}$ & 8 & 8 & 0 & 100 & \multirow[t]{5}{*}{$8.66 \times 10^{5}$} \\
\hline & $10^{8}$ & 8 & 7 & 1 & 87.5 & \\
\hline & $10^{7}$ & 8 & 7 & 1 & 87.5 & \\
\hline & $10^{6}$ & 8 & 4 & 4 & 50 & \\
\hline & $10^{5}$ & 8 & 2 & 6 & 25 & \\
\hline \multirow[t]{5}{*}{ APEC $94 \triangle \operatorname{sr}(C m)$} & $10^{9}$ & 8 & 7 & 1 & 87.5 & \multirow[t]{5}{*}{$2.55 \times 10^{8}$} \\
\hline & $10^{8}$ & 8 & 2 & 6 & 25 & \\
\hline & $10^{7}$ & 8 & 1 & 7 & 12.5 & \\
\hline & $10^{6}$ & 8 & 0 & 8 & 0 & \\
\hline & $10^{5}$ & 8 & 0 & 8 & 0 & \\
\hline
\end{tabular}



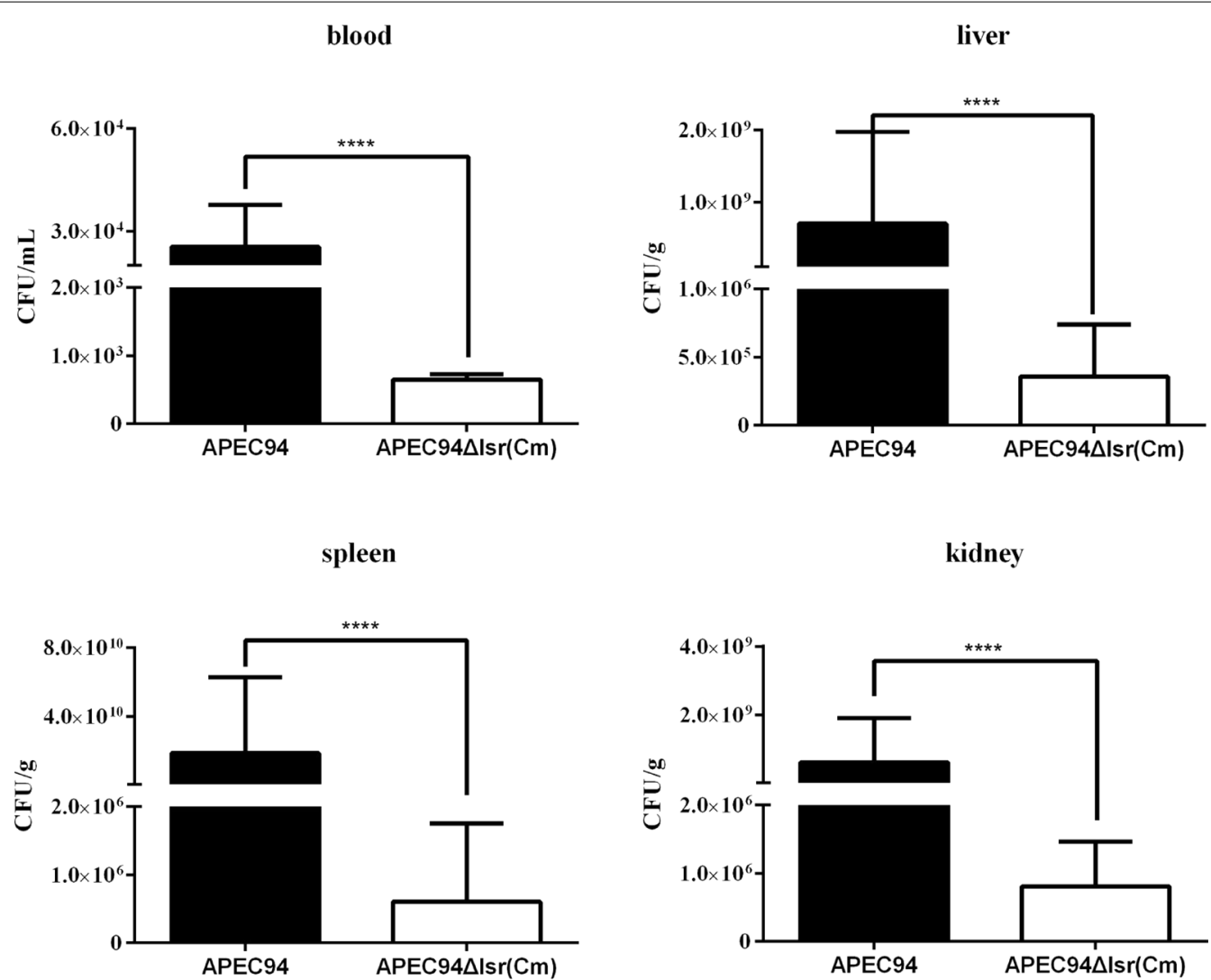

Figure 5 Bacterial survival in vivo. The bacterial loads in the blood, liver, spleen, and kidneys were counted. The data are reported per milliliter of blood, and per gram of liver, spleen, and kidney from the infected ducklings. The results showed that the bacterial loads of strain APEC94 $\triangle \mathrm{lsr}(\mathrm{Cm})$ in all of the samples were significantly lower than those infected with wild-type strain APEC94, being decreased by 38.5-, 1639-, 316 667-, and 753-fold, respectively $(p<0.0001)$.

were analyzed from three categories: biological process, cellular component, and molecular function (Figure 6B). The most enriched GO terms were associated with the localization and transport of different substances. Some terms could influence the components of the cellular membrane. Moreover, the number of down-regulated genes was significantly higher than that of up-regulated genes.

\section{Table 4 Bacterial loads in ducks}

\begin{tabular}{|c|c|c|c|}
\hline \multirow[t]{2}{*}{ Tissue and organ } & \multicolumn{2}{|c|}{ APEC strains } & \multirow[t]{2}{*}{ Fold change } \\
\hline & APEC94 &  & \\
\hline $\begin{array}{l}\text { Bacteria in blood (CFU/ } \\
\mathrm{mL} \text { ) }\end{array}$ & $2.5 \times 10^{4}$ & $6.5 \times 10^{2}$ & $38.5 \downarrow$ \\
\hline Bacteria in liver (CFU/g) & $5.9 \times 10^{8}$ & $3.6 \times 10^{5}$ & $1639 \downarrow$ \\
\hline Bacteria in spleen (CFU/g) & $1.9 \times 10^{10}$ & $6.0 \times 10^{5}$ & $316667 \downarrow$ \\
\hline Bacteria in kidney (CFU/g) & $6.1 \times 10^{8}$ & $8.1 \times 10^{5}$ & $735 \downarrow$ \\
\hline
\end{tabular}

" $\downarrow$ " means the fold change of bacterial loads of APEC $94 \Delta \mathrm{Isr}(\mathrm{Cm})$ in infected animals decreased compared with APEC94.

\section{The effect of $I s r$ operon on transcriptional profiles} of virulence-related genes

The qPCR results showed that the mRNA levels of five genes (i.e., fliD, $f h A$, dosP, pgaA and $f h u D$ ) were significantly decreased in $l s r$ mutant strain, as compared to APEC94 $(p<0.05)$. However, $p g a A$ and $f h u D$ mRNA levels did not restore in $l s r$ complementation strain $(p<0.05)$. There was no significant difference of fimH mRNA level between $l s r$ mutant strains and APEC94 $(p>0.05)$ (Figure 7).

\section{Discussion}

There is increasing awareness of the importance of quorum sensing in coordinating the cooperative behavior of bacteria in response to cell density. AI-2 is regarded as an inter-species communication molecule and its synthesis enzyme, LuxS, is widely distributed among bacteria.

Despite the large number of bacteria in which AI-2 has been detected, only two types of regulation mechanism for AI-2 internalization have been reported in Vibrio spp., Salmonella, and E. coli. In Vibrio spp., the lux 
A

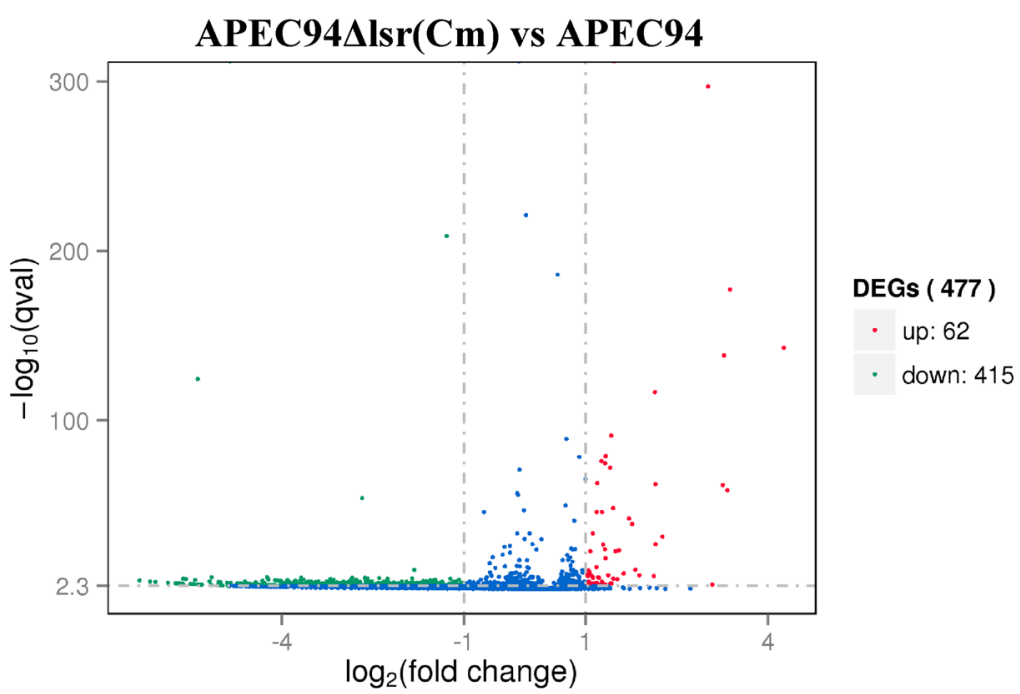

B

The Most Enriched GO Terms (APEC94Alsr(Cm) vs APEC94)

transport
establishment of localization -
localization -

single-organism transport -

single-organism localization -

carbohydrate transport -

organic substance transport -

transmembrane transport -

phosphoenolpyruvate-dependent ... aldonate transport -

carbohydrate transmembrane tran...

monocarboxylic acid transport

signal peptide processing

$\stackrel{\frac{E}{ \pm}}{Ð}$ organic anion transport organic acid transport

carboxylic acid transport

$\circlearrowleft$

cellular_component

integral component of membrane -

intrinsic component of membran... membrane part

cytoplasmic vesicle part -

signal peptidase complex peroxisome

transporter activity

carbohydrate transmembrane tra... carbohydrate transporter activ... gluconate transmembrane transp... aldonate transmembrane transpo... monocarboxylic acid transmembra.



type

biological_process cellular_component molecular_function

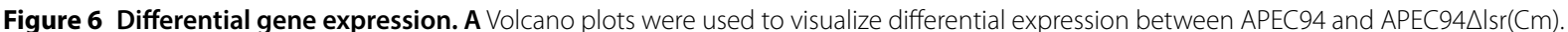
Genes with significantly up-regulated expression are indicated with red dots, down-regulated genes are indicated with green dots, and blue dots represent genes with no significant differential expression. The results showed that 62 genes were up-regulated and 415 genes were down-regulated in APEC $\triangle \mathrm{Is}(\mathrm{Cm})$, compared with wild-type strain APEC94 (differentially expressed genes were selected when the fold change was $>2$ and the q value $<0.005$ ). B The differentially expressed genes (including up-regulated and down-regulated genes) directly reflected the number and distribution of differentially expressed genes by GO term enriched from three categories: biological progress, cellular component and molecular function. ${ }^{*}$ Represents significantly enriched $(p<0.05)$. 


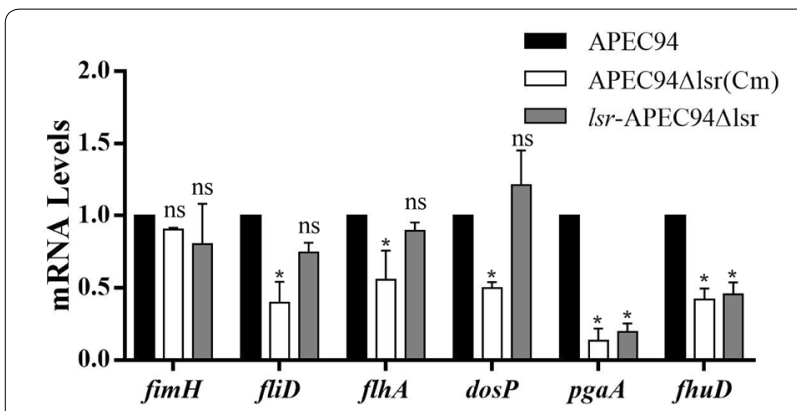

Figure 7 The effect of Isr operon on transcriptional profiles of virulence-related genes. The qPCR results showed that there was no significant difference of fimH mRNA level between Isr mutant strains and APEC94 or Isr-APEC94 $\triangle \mathrm{Isr}(p>0.05)$. However, the mRNA levels of five genes (fliD, flh $A$, dosP, pgaA and fhuD) were significantly decreased in Isr mutant strain, as compared to APEC94 $(p<0.05)$.

operon is involved in the response to signal transduction of AI-2 and LuxPQ-type of AI-2 receptor has only been found in Vibrio spp. [33]. The class of AI-2 receptors are periplasmic two-component sensor kinases and it is only the signal not the AI-2 molecule itself that is transduced intracellularly [33]. In Salmonella, the Lsr system is responsible for transferring AI-2 intracellularly and the LsrB-like AI-2 receptor is exposed on the cell surface [10]. This class of AI-2 receptors mainly found in the Enterobacteriaceae, Pasteurellaceae, Rhizobiaceae, and Bacillaceae, but are not detected in APEC [4].

The Lsr operon has been shown to be the transport system for AI-2 in E. coli. LuxS was also detected in APEC in our previous studies. However, Pereira et al. reported that no similar Lsr transport system was able to be detected in APEC [4]. This was in agreement with our previous study in one serotype O2 APEC strain DE17, which could internalize AI-2. Furthermore, in the present study, the $l s r$ operon genes were not detected in some APEC strains. However, interestingly, the $l s r$ operon was identified in APEC94. To analyze the connection between the $l s r$ operon distribution and $\mathrm{O}$-antigen serotypes, we detected the presence of the $l s r$ operon in the main serotypes $(\mathrm{O} 1, \mathrm{O} 2$, and O78) of APEC. Our findings supported our hypothesis that the lsr operon is only present in some APEC strains, although it was present in all three serotypes (O1, O2 and O78). The highest prevalence (95.5\%) of the lsr operon was detected among serotype 078 strains, followed by serotype O1 strains $(68.8 \%)$, and serotype O2 strains (40.9\%). This may show the divergence between serotypes that has occurred during the evolution of APEC. Five strains were detected with incomplete operons, potentially caused by mutagenesis during the process of evolution. However, the evolutionary basis for these genetic differences requires further study.

In the current study, the lsr operon was unable to be amplified from 19 APEC strains, which represented a comparatively high frequency $(31.7 \%)$ of the strains tested. As APEC was able to remove AI-2 from the culture medium in previous studies, it was proposed that another transport system may be functioning in AI-2 internalization [2]. It was also proposed that some lowaffinity transport system may also be operating to internalize AI-2 in E. coli, as E. coli lsr CDB mutants are still capable of slowly removing AI-2 from culture fluids [10]. Recently, our studies showed that the ptsI gene encodes enzyme I, which participates in the phosphotransferase system (PTS) that regulates virulence and AI-2 internalization in APEC [22]. The existence of a new type of AI-2 transport system in APEC and other species is still under investigation and its discovery could potentially offer a therapeutic alternative to antibiotics.

LsrB, encoded by one of the $l s r$ operon genes, was first shown to be the receptor for AI-2 in S. typhimurium. Orthologs of LsrB were then successively characterized in other bacteria and shown to have AI-2 binding activity [4]. In this study, to assess whether LsrB of APEC has AI- 2 binding activity, the $l s r B$ gene was expressed in both BL21 and BL21 luxS strains. Our previous studies showed that strain BL21(DE3) could generate endogenous AI-2, which interfered with LsrB binding or the release of AI-2. However, the luxS mutant of strain BL21 could not produce AI-2 and no sign of interference with LsrB binding and the release of AI- 2 was observed. The present study also showed that LsrB of APEC had AI-2 binding activity.

The Lsr system is involved in mediating bacterial uptake of AI-2 from the extracellular environment in many bacteria including Salmonella typhi and E. coli [4, 6]. In the lsr operon, phosphorylated AI-2 is produced by the LsrK protein, along with the consumption of ATP, and a $l s r K$ mutant would be defective in the importation of AI-2 from culture fluids. The regulation of the $l s r$ operon by transport, phosphorylation and processing of phosphor-AI-2 proceeds through the inactivation of the LsrR repressor [4]. In both S. typhimurium and E. coli, LsrB was shown to be the receptor for AI-2. To further determine the roles of the lsr operon in the transport of AI-2 in APEC, the $l s r$ operon was deleted to generate mutant strain APEC $94 \Delta \mathrm{lsr}(\mathrm{Cm})$, which was defective in the AI-2 internalization pathway. Thus, in exponential phase, defects in transport meant that AI-2 levels were greater with mutant strain APEC $94 \Delta \mathrm{lsr}(\mathrm{Cm})$ than for the wild-type strain. The AI-2 internalization curves of APEC94 and APEC94 $\triangle \mathrm{lsr}(\mathrm{Cm})$ further confirmed the 
role of the $l s r$ operon in the uptake of AI-2, and the deletion of $l s r$ inhibited AI-2 internalization.

The LuxS/AI-2 quorum sensing system has been shown to regulate bacterial behavior including biofilm formation and virulence. Bacterial motility plays an important role in many aspects of bacterial pathogenicity [34] and has been found to involve several genes, such as the flagellar biosynthesis genes in Helicobacter pylori, the biofilm formation genes in MG1655, and luxS in APEC [1, 35, $36]$. In this study, mutation of the $l s r$ operon significantly decreased the motility of APEC94 on soft agar plates. Possible explanations for this include: (1) transcription of related flagella biosynthesis genes was restricted and led to the loss of flagella and defective motility, such as in Aeromonas hydrophila [35]; (2) the levels of $3^{\prime}, 5^{\prime}$-cyclic diguanylic acid (c-di-GMP) were altered by mutation of the $l s r$ operon, such as seen in Clostridium difficile, culminating in reduced motility [37]. In our subsequent transcriptome assay, the decreased transcription of some flagella biosynthesis genes, such as fliI, fliF, flhA, $f l h B$, $m o t B$, and $f l K$, supported this. However, the molecular mechanisms involved require further analysis.

Our previous studies showed that the luxS gene was associated with the pathogenesis of APEC, and that mutation of this gene attenuated the virulence of APEC [1]. However, the precise role of AI-2 signaling in APEC is not clear and remains to be demonstrated whether the $l s r$ operon is involved in mediating the virulence of APEC. In this study, the $\mathrm{LD}_{50}$ of APEC $94 \Delta \mathrm{lsr}(\mathrm{Cm})$ was decreased by 294 -fold. A similar trend was also observed for bacterial survival in an in vivo assay. Distinct attenuation of the bacterial load in the blood, liver, spleen, and kidneys of ducks infected with APEC $94 \Delta \operatorname{lsr}(\mathrm{Cm})$ was evidenced compared with ducks infected with wild-type strain APEC94. The results of animal experiments indicated that the Lsr system is involved in mediating the virulence of APEC but the mechanism responsible for the decreased virulence of APEC $94 \Delta \mathrm{lsr}(\mathrm{Cm})$ remains to be determined.

This phenomenon might be caused by down-regulation of certain virulence genes including those involved in mediating bacterial motility, iron metabolism, and survival in host cells. The motility assay showed that the motility of APEC $94 \Delta \operatorname{lsr}(\mathrm{Cm})$ was impaired, confirming the role of the $l s r$ operon. This was further supported by transcriptomic analysis of the APEC 94 and APEC $94 \triangle \mathrm{lsr}(\mathrm{Cm})$ strains. The expression of other genes was also affected by deletion of the $l s r$ operon, leading to significantly decreased transcription levels. For example, the fep $G$ and $f e p E$ genes that encode ferric proteins involved in enterobactin uptake and export were downregulated in expression by 2.8368 - and 4.2153-fold, respectively [38, 39]. In many E. coli and $S$. typhimurium strains, the ferric enterobactin transporter facilitates iron uptake and plays a role in the defense against various sources of oxidative stress [3941]. Another example was the fimD gene that encodes a fimbrial biogenesis outer membrane usher protein that is crucial for usher gating of type I pili, which was downregulated in expression by 16-fold [42]. Outer membrane proteins play an essential role in the rapid adaptation of Gram-negative bacteria to changes in their environment. Fimbriae, an important component of the outer membrane, plays a vital role in APEC during the adherence to and invasion of host cells and FimD is associated with virulence [43].

Furthermore, another 6 genes involved in type III export system, c-di-GMP and biofilm formation, were selected for further evaluating the effects of $l s r$ operon on biological characteristics of APEC by q-PCR. For example, the flagellin protein FliD plays a role in flagellin polymerization. Deletion of fliD of Salmonella could induce a lower expression of immune genes in infected chicken embryo fibroblasts [28, 44]. FlhA is a membrane-protein subunit of the bacterial flagellar type III export system, which functions in many gram-negative pathogens to export virulence factors into host cells [29]. DosP was reported with multiple biological functions, such as cleaving both c-di-GMP and cAMP [30]. PgaA is required for the formation of polymeric $\beta-1,6-N$-acetylD-glucosamine (poly- $\beta-1,6-$ GlcNAc), which has been implicated as an E. coli biofilm adhesin [31]. The FhuD is a necessary component of the hydroxamate siderophore transport system [32]. The present results showed that deletion of $l s r$ decreased transcriptional levels of $f l i D$, $f l h A, \operatorname{dos} P, p g a A$ and $f h u D$, which also explained the possible reason for decreasing pathogenicity of $l s r$ mutant strain. However, the transcriptional level of genes $\mathrm{pgaA}$ and $f h u D$ did not restored in $l s r$-APEC $94 \Delta$ lsr. A possible reason was that the transcriptional level of $l s r$ operon genes of complement strain were higher than that of wild strain, which affected the expression of $p g a A$ and $f h u D$ in $l s r$-APEC94 $\triangle \mathrm{lsr}$. The underlying mechanisms still need to be further studied.

In conclusion, our study showed that the distribution of the $l s r$ operon was associated with different serotypes of APEC and affected the motility of bacterial cells, AI-2 uptake, and pathogenesis. This study provides a basis for further functional research into the role of $l s r$ operon in APEC.

\section{Supplementary information}

Supplementary information accompanies this paper at https://doi. org/10.1186/s13567-019-0725-0. 


\section{Additional file 1. The distribution of Isr operon in APEC strains.}

Additional file 2. Nucleotide sequence identities of APEC94 compared with E. coli MG1655 and Salmonella TL2.

\section{Additional file 3. Amino acid sequence identities of APEC94 com-} pared with E. coli MG1655 and Salmonella TL2.

\section{Acknowledgements}

This work was supported by the National Natural Science Foundation of China (31572546, 31872483 and 31772707), the Shanghai Science and Technology Standard Fund (Grant No.18140900700 and 17140900400), National Basic Fund for Research Institutes, which is supported by the Chinese Academy of Agricultural Sciences (2019JB01) and the open projects of key laboratory for poultry genetics and breeding of Jiangsu province (JQLAB-KF-201802).

\section{Authors' contributions}

$\mathrm{XH}$ and $\mathrm{JM}$ participated in the design of the study. JZ, JH, HY and ZW performed the experiments and analyzed the data. JZ and XH prepared the manuscript. RM, ZC, WJ, YH and JG contributed reagents, materials and analysis tools. $\mathrm{XH}, \mathrm{KQ}, \mathrm{CW}$ and $\mathrm{VP}$ revised the manuscript. All authors read and approved the final manuscript.

\section{Ethics statements}

According to the guidelines of the Institutional Animal Care and Use Committee (IACUS), one-day-old Cherry Valley ducklings purchased from Shangha Zhuang Hang Duck Farm were cared for and maintained by the Shanghai Veterinary Research Institute of Chinese Academy of Agricultural Sciences (CAAS). All the animal experiments were approved by the Ethics Committee of CAAS (Permit No: CAAS-SHVRI-Po-2019-36).

\section{Competing interests}

The authors declare that they have no competing interests.

\section{Author details}

1 Shanghai Veterinary Research Institute, The Chinese Academy of Agricultural Sciences (CAAS), 518 Ziyue Road, Shanghai 200241, People's Republic of China. ${ }^{2}$ College of Life Science, Longyan University, Longyan 364000, People's Republic of China. ${ }^{3}$ College of Animal Science and Technology, Anhui Agricultural University, Hefei 230036, People's Republic of China. ${ }^{4}$ College of Veterinary Medicine, Nanjing Agricultural University, Nanjing 210095, People's Republic of China. ${ }^{5}$ Poultry Institute, Chinese Academy of Agricultural Sciences, Yangzhou 225125, People's Republic of China. ${ }^{6}$ Biotechnology and Ecology Institute, Ministry of Science and Technology (MOST), Vientiane 22797, Lao PDR. ${ }^{7}$ College of Animal Science and Technology, Henan University of Science and Technology, No. 263 Kaiyuan Road, Luoyang 471023, People's Republic of China.

Received: 8 June 2019 Accepted: 12 November 2019

Published online: 12 December 2019

\section{References}

1. Han X, Bai H, Tu J, Yang L, Xu D, Wang S, Qi K, Fan G, Zhang Y, Zuo J, Tian M, Ding C, Yu S (2015) Deletion of luxS further attenuates the virulence of the avian pathogenic Escherichia coli aroA mutant. Microb Pathog 88:39-47

2. Han X, Bai H, Liu L, Dong H, Liu R, Song J, Ding C, Qi K, Liu H, Yu S (2013) The luxS gene functions in the pathogenesis of avian pathogenic Escherichia coli. Microb Pathog 55:21-27

3. Han X, Liu L, Fan G, Zhang Y, Xu D, Zuo J, Wang S, Wang X, Tian M, Ding C, Yu S (2015) Riemerella anatipestifer lacks luxS, but can uptake exogenous autoinducer-2 to regulate biofilm formation. Res Microbiol 166:486-493

4. Pereira CS, de Regt AK, Brito PH, Miller ST, Xavier KB (2009) Identification of functional LsrB-like autoinducer-2 receptors. J Bacteriol 191:6975-6987

5. Miller ST, Xavier KB, Campagna SR, Taga ME, Semmelhack MF, Bassler BL, Hughson FM (2004) Salmonella typhimurium recognizes a chemically distinct form of the bacterial quorum-sensing signal Al-2. Mol Cell 15:677-687
6. Taga ME, Miller ST, Bassler BL (2003) Lsr-mediated transport and processing of Al-2 in Salmonella typhimurium. Mol Microbiol 50:1411-1427

7. Xue T, Zhao L, Sun H, Zhou X, Sun B (2009) LsrR-binding site recognition and regulatory characteristics in Escherichia coli Al-2 quorum sensing. Cell Res 19:1258-1268

8. Marques JC, Oh IK, Ly DC, Lamosa P, Ventura MR, Miller ST, Xavier KB (2014) LsrF, a coenzyme A-dependent thiolase, catalyzes the terminal step in processing the quorum sensing signal autoinducer-2. Proc Natl Acad Sci USA 111:14235-14240

9. Taga ME, Semmelhack JL, Bassler BL (2001) The LuxS-dependent autoinducer $\mathrm{Al}-2$ controls the expression of an $\mathrm{ABC}$ transporter that functions in Al-2 uptake in Salmonella typhimurium. Mol Microbiol 42:777-793

10. Xavier KB, Bassler BL (2005) Regulation of uptake and processing of the quorum-sensing autoinducer Al-2 in Escherichia coli. J Bacteriol 187:238-248

11. Pereira CS, McAuley JR, Taga ME, Xavier KB, Miller ST (2008) Sinorhizobium meliloti, a bacterium lacking the autoinducer-2 (Al-2) synthase, responds to Al-2 supplied by other bacteria. Mol Microbiol 70:1223-1235

12. Shao H, James D, Lamont RJ, Demuth DR (2007) Differential interaction of Aggregatibacter (Actinobacillus) actinomycetemcomitans LsrB and RbsB proteins with autoinducer 2. J Bacteriol 189:5559-5565

13. Bassler BL, Wright M, Showalter RE, Silverman MR (1993) Intercellular signalling in Vibrio harveyi: sequence and function of genes regulating expression of luminescence. Mol Microbiol 9:773-786

14. Cheng HR, Jiang N (2006) Extremely rapid extraction of DNA from bacteria and yeasts. Biotechnol Lett 28:55-59

15. Wang S, Meng Q, Dai J, Han X, Han Y, Ding C, Liu H, Yu S (2014) Development of an allele-specific PCR assay for simultaneous sero-typing of avian pathogenic Escherichia coli predominant O1, O2, 018 and 078 strains. PLOS ONE 9:e96904

16. Blattner FR, Plunkett G 3rd, Bloch CA, Perna NT, Burland V, Riley M, Collado-Vides J, Glasner JD, Rode CK, Mayhew GF, Gregor J, Davis NW, Kirkpatrick HA, Goeden MA, Rose DJ, Mau B, Shao Y (1997) The complete genome sequence of Escherichia coli K-12. Science 277:1453-1462

17. Datsenko KA, Wanner BL (2000) One-step inactivation of chromosomal genes in Escherichia coli K-12 using PCR products. Proc Natl Acad Sci USA 97:6640-6645

18. Wang X, Ding C, Wang S, Han X, Hou W, Yue J, Zou J, Yu S (2014) The AS87_04050 gene is involved in bacterial lipopolysaccharide biosynthesis and pathogenicity of Riemerella anatipestifer. PLoS One 9:e109962

19. Ling H, Kang A, Tan MH, Qi X, Chang MW (2010) The absence of the luxS gene increases swimming motility and flagella synthesis in Escherichia coli K12. Biochem Biophys Res Commun 401:521-526

20. Han X, Lu C (2009) Biological activity and identification of a peptide inhibitor of LuxS from Streptococcus suis serotype 2. FEMS Microbiol Lett 294:16-23

21. Bassler BL, Wright M, Silverman MR (1994) Multiple signalling systems controlling expression of luminescence in Vibrio harveyi: sequence and function of genes encoding a second sensory pathway. Mol Microbiol 13:273-286

22. Wu X, Lv X, Lu J, Yu S, Jin Y, Hu J, Zuo J, Mi R, Huang Y, Qi K, Chen Z, Han X (2017) The role of the $p t s /$ gene on Al-2 internalization and pathogenesis of avian pathogenic Escherichia coli. Microb Pathog 113:321-329

23. Zhang Y, Qi K, Jing Y, Zuo J, Hu J, Lv X, Chen Z, Mi R, Huang Y, Yu S, Han X (2017) LsrB-based and temperature-dependent identification of bacterial Al-2 receptor. AMB Express 7:188

24. Xu D, Zuo J, Chen Z, Lv X, Hu J, Wu X, Qi K, Mi R, Huang Y, Miao J, Jiang W, Wang S, Wang C, Han X (2017) Different activated methyl cycle pathways affect the pathogenicity of avian pathogenic Escherichia coli. Vet Microbiol 211:160-168

25. Reed $\sqcup$, Muench $H$ (1938) A simple method of estimating fifty percent endpoints. Am J Hyg 27:493-497

26. Tian M, Qu J, Han X, Zhang M, Ding C, Ding J, Chen G, Yu S (2013) Microarray-based identification of differentially expressed genes in intracellular Brucella abortus within RAW264.7 cells. PLoS One 8:e67014

27. Russell CW, Fleming BA, Jost CA, Tran A, Stenquist AT, Wambaugh MA, Bronner MP, Mulvey MA (2018) Context-dependent requirements for FimH and other canonical virulence factors in gut colonization by extraintestinal pathogenic Escherichia coli. Infect Immun 86:e0746-17 
28. Song WS, Cho SY, Hong HJ, Park SC, Yoon SI (2017) Self-oligomerizing structure of the flagellar cap protein FliD and its implication in filament assembly. J Mol Biol 429:847-857

29. Erhardt M, Wheatley P, Kim EA, Hirano T, Zhang Y, Sarkar MK, Hughes KT, Blair DF (2017) Mechanism of type-III protein secretion: regulation of FlhA conformation by a functionally critical charged-residue cluster. Mol Microbiol 104:234-249

30. Kwan BW, Osbourne DO, Hu Y, Benedik MJ, Wood TK (2015) Phosphodiesterase DosP increases persistence by reducing CAMP which reduces the signal indole. Biotechnol Bioeng 112:588-600

31. Itoh Y, Wang X, Hinnebusch BJ, Preston JF 3rd, Romeo T (2005) Depolymerization of beta-1,6- $\mathrm{N}$-acetyl-D-glucosamine disrupts the integrity of diverse bacterial biofilms. J Bacteriol 187:382-387

32. Carter DM, Miousse IR, Gagnon JN, Martinez E, Clements A, Lee J, Hancock MA, Gagnon H, Pawelek PD, Coulton JW (2006) Interactions between TonB from Escherichia coli and the periplasmic protein FhuD. J Biol Chem 281:35413-35424

33. Freeman JA, Bassler BL (1999) A genetic analysis of the function of LuxO, a two-component response regulator involved in quorum sensing in Vibrio harveyi. Vet Microbiol 31:665-677

34. Lertsethtakarn P, Ottemann KM, Hendrixson DR (2011) Motility and chemotaxis in Campylobacter and Helicobacter. Annu Rev Microbiol 65:389-410

35. Shen F, Hobley L, Doherty N, Loh JT, Cover TL, Sockett RE, Hardie KR, Atherton JC (2010) In Helicobacter pylori auto-inducer-2, but not LuxS/ MccAB catalysed reverse transsulphuration, regulates motility through modulation of flagellar gene transcription. BMC Microbiol 10:210

36. Gonzalez Barrios AF, Zuo R, Hashimoto Y, Yang L, Bentley WE, Wood TK (2006) Autoinducer 2 controls biofilm formation in Escherichia coli through a novel motility quorum-sensing regulator (MqsR, B3022). J Bacteriol 188:305-316
37. Purcell EB, McKee RW, McBride SM, Waters CM, Tamayo R (2012) Cyclic diguanylate inversely regulates motility and aggregation in Clostridium difficile. J Bacteriol 194:3307-3316

38. Fernandez L, Marquez I, Guijarro JA (2004) Identification of specific in vivo-induced (ivi) genes in Yersinia ruckeri and analysis of ruckerbactin, a catecholate siderophore iron acquisition system. Appl Environ Microb 70:5199-5207

39. Peralta DR, Adler C, Corbalan NS, Paz Garcia EC, Pomares MF, Vincent PA (2016) Enterobactin as part of the oxidative stress response repertoire. PLoS One 11:e0157799

40. Ozenberger BA, Nahlik MS, McIntosh MA (1987) Genetic organization of multiple fep genes encoding ferric enterobactin transport functions in Escherichia coli. J Bacteriol 169:3638-3646

41. Newton SM, Trinh V, Pi H, Klebba PE (2010) Direct measurements of the outer membrane stage of ferric enterobactin transport: postuptake binding. J Biol Chem 285:17488-17497

42. Volkan E, Kalas V, Pinkner JS, Dodson KW, Henderson NS, Pham T, Waksman G, Delcour AH, Thanassi DG, Hultgren SJ (2013) Molecular basis of usher pore gating in Escherichia coli pilus biogenesis. Proc Natl Acad Sci USA 110:20741-20746

43. Ghunaim H, Abu-Madi MA, Kariyawasam S (2014) Advances in vaccination against avian pathogenic Escherichia coli respiratory disease: potentials and limitations. Vet Microbiol 172:13-22

44. Szmolka A, Matulova ME, Rychlik I (2018) Impact of fliD and virulence plasmid pSEV on response of chicken embryo fibroblasts to Salmonella Enteritidis. Vet Immunol Immunopathol 196:1-4

\section{Publisher's Note}

Springer Nature remains neutral with regard to jurisdictional claims in published maps and institutional affiliations.
Ready to submit your research? Choose BMC and benefit from:

- fast, convenient online submission

- thorough peer review by experienced researchers in your field

- rapid publication on acceptance

- support for research data, including large and complex data types

- gold Open Access which fosters wider collaboration and increased citations

- maximum visibility for your research: over $100 \mathrm{M}$ website views per year

At $\mathrm{BMC}$, research is always in progress.

Learn more biomedcentral.com/submissions 